Short Report

\section{Importance of acidic intracellular compartments in the lysis of Trypanosoma brucei brucei by normal human serum}

Patrick Lorenz, Philip E. Barth, Werner Rudin and Bruno Betschart ${ }^{*}$ Swiss iropical Institute, Postfach, CH 4002 Basel, Swizerland

The unicellular parasite Trypanosoma brucei brucei is unable to infect healthy humans due to its sensitivity to a component of normal human scrum (NHS), high density lipoprotein (HDL) (RIFKIN, 1978; LORENZ el al., 1994). Unable to synthesize essential lipids de novo, T.b. brucei bloodstrean forms are obliged to assimilate these compounds from their host. HDL and low density lipoproteins (LDL) can supply the required lipids (BLACK \& VANDEWEERD, 1989) and high affinity receptors for both lipoproteins are present on the parasites (COPPENS et al., 1988; GILLETT \& OWEN, 1992). Whereas LDL is known to bind to the trypanosomal cell surface in the area of the flagellar pocket followed by internalization and delivery to endosome/lysosome-like compartments (COPPENS et al., 1987), the interaction between T.b. brucet and human HDL and the molecular events leading to cell lysis are not well understood. Clearly, after a lag phase of $20-30 \mathrm{~min}$ at $37^{\circ} \mathrm{C}$ in medium containing NHS, the plasma membrane of the trypanosomes is damaged resulting in increased permeability, osmotic swelling and lysis (RIFKIN, 1984)

We present evidence that acidic intracellular compart-

\section{CONCENTRATION (Monensin)}

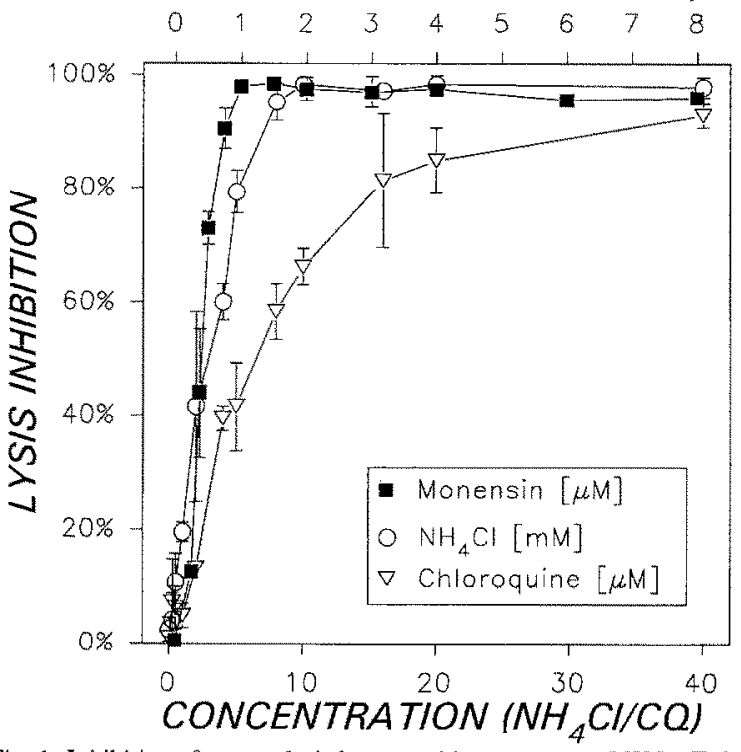

Fig. 1. Inhibition of trypandysis by normal human serum (NHS). $T . b$ brucei (STIB 345AD) was isolated $72 \mathrm{~h}$ after infection of ICR mice, incubated in vitro at $37^{\circ} \mathrm{C}$ in minimal essential medium (MEM) containing $30 \%$ NHS, $10 \%$ horse serum (LORENZ et al., 1994) plus various concentrations of $\mathrm{NH} 4 \mathrm{Cl}$ (Merck), chloroquine (Sigma) or monensin (Sigma) After $4 \mathrm{~h}$ (monensin $3.3 \mathrm{~h}$ ), lysis was calculated by determining the proportion of swollen/ysed cells in the population using phase-contrast microscopy ( $200 \times$ magnification). Lysis was normalized to give $100 \%$ for the highest observed value and lysis inhibition ( $\%$ ) was calculated by subtracting the normalized values from $100 \%$. Values are means of duplicate or triplicate assays (vertical bars indicate standard deviation, $\geqslant 100$ cells counted per incubation).
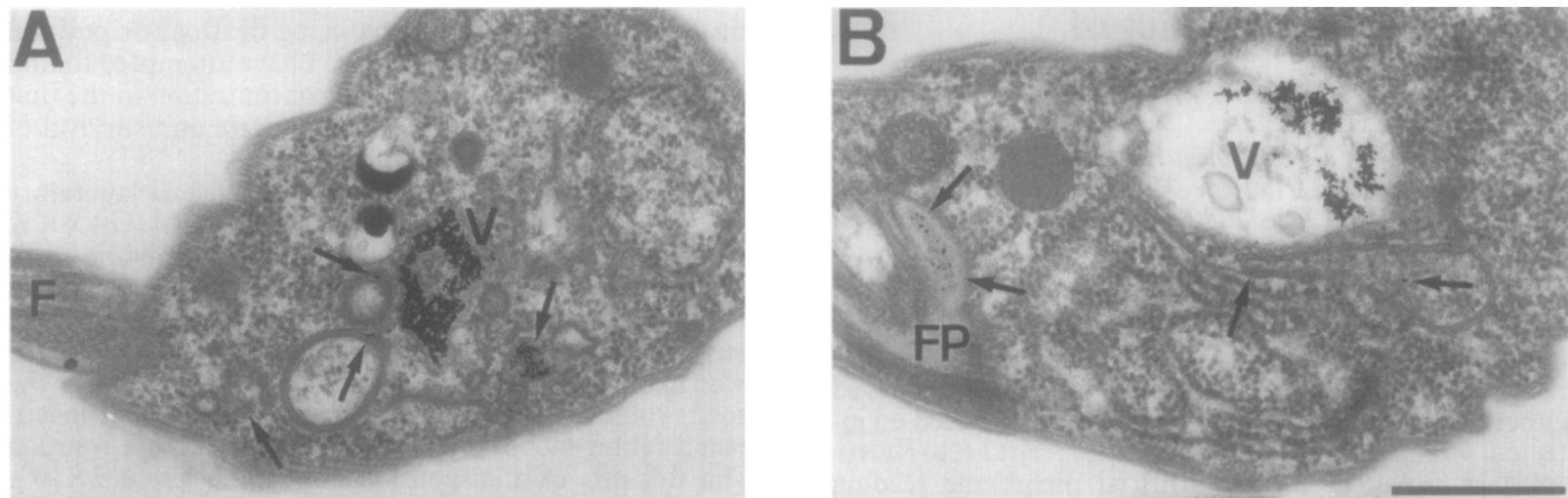

Fig. 2. Effect of $\mathrm{NH}_{4} \mathrm{Cl}$ on uptake of high density lipoproteins (HDL) by $T$. b. brucei. Trypanosomes (prepared as described in Fig. 1) were incubated for $60 \mathrm{~min}$ at $37^{\circ} \mathrm{C}$ in $\mathrm{MEM}$ (plus $5 \mathrm{mM}$ EDTA, without $\mathrm{Ca}^{2+} / \mathrm{Mg}^{2+}$ phosphate), $1 \%$ bovine serum albumin, 50 ug/mL human $\mathrm{HDL}$ (icles) (HDL pruvided by DT J. S. Owen) whout (A) or with (B) $20 \mathrm{~mm} \mathrm{NH}$ Cl and processed for electron microscopy. A. Endocytosed HDL 3 -gold particles are found within tubulovesicular structures (arrows) and amassed in large vacuolar structures. $B$. The same endocytic organelles are labelled in the presence of $\mathrm{NH}_{4} \mathrm{Cl}$, but the large vacuoles are dilated in a fashion characteristic of acidic compartments (e.g. lysosomes; CoppeNs et al., 1993). $\mathrm{F}$, flagellum; $\mathrm{FP}$, flagellar pocket; $V$, vacuolelysosome. Scale bar $0.5 \mathrm{~km}$

ments known to be involved in processes such as receptor recycling, membrane traffic, degradation of endocytosed macromolecules, and toxin activation in mammalian cells (MELLMAN et al., 1986) and, importantly, in the LDL metabolism of $T . b$. brucei (see CorPENs et al., 1993) are also involved in HDL-mediated trypanolysis. The lysosomotropic weak bases ammonium chloride $\left(\mathrm{NH}_{4} \mathrm{Cl}\right.$ ) and chloroquine (CQ) and the carboxylic ionophore monensin, which raise the $\mathrm{pH}$ in intracellular compartments and inhibit the above processes, completely inhibited trypanolysis in an assay in vitro (Fig. 1). T. $b$. brucei could even be cultivated in vitro for $4 \mathrm{~d}$ on a Microtus montanus embryo fibroblast feeder layer in the

"Author for correspondence. presence of $20 \% \mathrm{NHS}$ and $20 \mathrm{mM} \mathrm{NH}_{4} \mathrm{Cl}$ (data not shown). Furthermore, it seems that, in analogy with LDL (COPPENS et al., 1988), gold-coupled human $\mathrm{HDL}_{3}$ is internalized by $T . b$. brucei and directed to lysosomal compartments (Fig. 2, A). The uptake is not abrogated, but only marginally slowed, if $\mathrm{NH}_{4} \mathrm{Cl}$ is present (Fig. 2, B and other data not shown). Which of the pHdependent processes listed above is required for trypanolysis is unclear. The observation that trypanolysis does not occur, despite HDL uptake, indicates that additional $\mathrm{pH}$-dependent processes (e.g. toxin activation or metabolic degradation) may be required to cause cell lysis. The data presented are consistent with a model of trypanolysis suggested by BETSCHART et al. (1989) and elaborated by HAJDUK et al. (1992), involving binding of try- 
panolytic HDL to cell surface receptors followed by internalization and delivery to acidic intracellular compartments.

\section{References}

Betschart, B., Barth, P. \& Jenni, L. (1989). Weak bases as inhibitors of the trypanocidal activity of human serum. In: Protein Traffic in Parasites and Mammalian Cells: Proceedings of a Workshop held at the International Laboratory for Research on Animal Diseases, Nairobi, Kenya, 29 August to 1 September 1988 , pp. 25-29.

Black, S. J. \& Vandeweerd, V. (1989). Serum lipoproteins are required for multiplication of Trypanosoma brucei under axenic culture conditions. Molecular and Biochemical Parasitology, 37, 65-72.

Coppens, I., Opperdoes, F. R., Courtoy, P. J. \& Baudhuin, P. (1987). Receptor-mediated endocytosis in the bloodstream form of Trypanosoma brucei. Fournal of Protozoology, 34, 465473.

Coppens, I., Baudhuin, P., Opperdoes, F. R. \& Courtoy, P. J. (1988). Receptors for the host low density lipoproteins on the hemoflagellate Trypanosoma brucei: purification and in volvement in the growth of the parasite. Proceedings of the National Academy of Sciences of the USA, 85, 6753-6757.

Coppens, I., Baudhuin, P., Opperdoes, F. R. \& Courtoy, P. J (1993). Role of acidic compartments in Trypanosoma brucei, with special reference to low-density lipoprotein processing. Molecular and Biochemical Parasitology, 58, 223-232.

Gillett, M. P. T. \& Owen, J. S. (1992). Characteristics of the binding of human and bovine high-density lipoproteins by the bloodstream forms of the African trypanosome, Trypanosome brucei brucei. Biochimica et Biophysica Acta, 1123, 239248.

Hajduk, S. L., Hager, K. \& Esko, J. D. (1992). High-density lipoprotein-mediated lysis of trypanosomes. Parasitology Today, 8, 95-98

Lorenz, P., James, R. W., Owen, J. S. \& Betschart, B. (1994). Heterogeneity in the properties of the trypanolytic factor in normal human serum. Molecular and Biochemical Parasitology, 64, 153-164.

Mellman, I., Fuchs, R. \& Helenius, A. (1986). Acidification of the endocytic and exocytic pathways. Annual Review of Biochemistry, 55, 663-700.

Rifkin, M. R. (1978). Identification of the trypanocidal factor in normal human serum: high density lipoprotein. Proceedings of the National Academy of Sciences of the USA, 75, 34503454.

Rifkin, M. R. (1984). Trypanosoma brucei: biochemical and morphological studies of cytotoxicity caused by normal human serum. Experimental Parasitology, 58, 81-93.

Received 17 March 1994; accepted for publication 17 May 1994

\section{Short Report}

\section{A modified artificial membrane feeding method for the study of the transmission dynamics of leishmaniasis}

K. N. Ghosh Yale Arbovims Research Unit, Department of Epidemiology and Public Health, School of Medicine, 60 College Street, P.O. Box 208034, New Haven, Connecticut $06520-8034$, USA

Study of the transmission dynamics of leishmaniasis has recently undergone a resurgence of interest. Experimental infection of sandflies is usually achieved either by allowing laboratory-bred sandflies to feed on infected animals (SHORTT et al., 1931; KILLICK-KENDRICK et al., 1977) or by artificial membrane feeding methods (ADLER \& BER, 1941; POZIO et al., 1985). The difference between the 2 approaches is that in the latter the parasite concentration in the infective meal can be controlled, while in the former parasite abundance in the skin is comparatively low and, in the case of visceral leishmaniasis, even the presence of parasites is unpredictable.
Giving a second blood meal to sandflies is always a problem as most of them die at oviposition and a second feed before oviposition is not always possible as most of the flies are gonotrophically concordant (KILLICKKENDRICK, 1987). SHORTT et al. (1926), working with Phlebotomus argentipes, a gonotrophically concordant fly, investigated many ways of reducing death at oviposition but without encouraging results. I have attempted to find out whether reducing the blood concentration in the first feed had any effect on the infection rate and survival of sandflies.

The sandflies used were from a established laboratory colony of $P$. argentipes Annandale \& Brunelti (GrosH \& BHATTACHARYA, 1989). Details of the membrane feeding technique have been described by GHOSH et al. (1989), except that the constitution of the blood-parasite suspension was varied. The suspension (about $2.3 \mathrm{~mL}$ ) was made up of about $0.7 \mathrm{~mL}$ (almost one-third of the total volume) of defibrinated and complement-inactivated rabbit blood, $0.8 \mathrm{~mL}$ of $0.254 \mathrm{M}$ sucrose solution and $0.8 \mathrm{~mL}$ of a suspension containing about $2 \times 10^{6}$ $4 \times 10^{6} / \mathrm{mL}$ of Leishmania donovani (MHOM/IN/90/GE6) (amastigotes in group A experiments, promastigotes in group B) in phosphate-buffered saline solution (PBS) at pH 7.2. The promastigotes were grown in modified biphasic Tobie's medium (TOBIE et al., 1950), while macerated spleen of infected Balb/c mice served as the sourcc of amastigotes. As a control, a proportion of the flies

Table. Results of membrane feeding and subsequent animal feeding of Phlebotomus argentipes

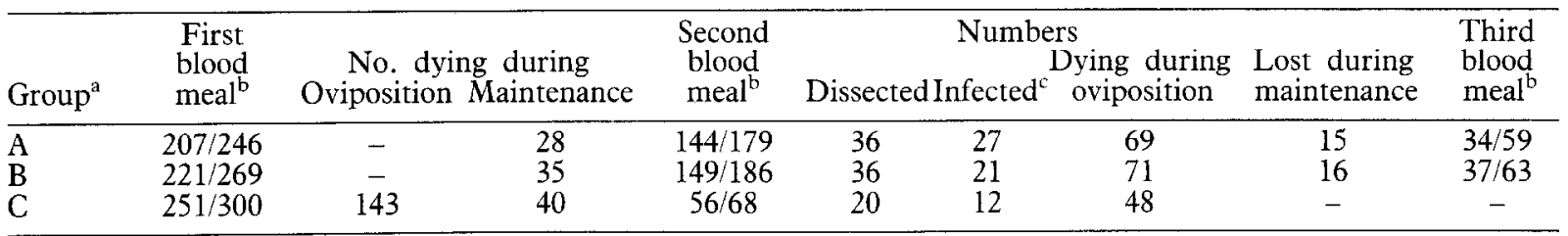

${ }^{\mathrm{a}}$ Each group represents the total of 4 trials.

bo. feeding/no. offered food. First blood meal contained Leishmania in membrane feeding apparatus; second and third meals were on uninfected hamsters or mice.

${ }^{c}$ Containing Leishmania promastigotes. 